Nature Library

THE BIRDS OF MANITOBA. Reviewed by C. Stuart Houston

NEW NATURAL HISTORY BOOKS 1974-75. Sheila Purse . . . . . . . . . . . . 254

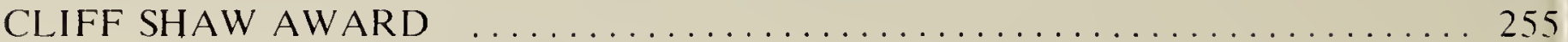

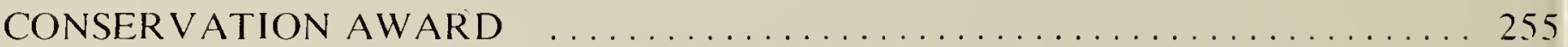

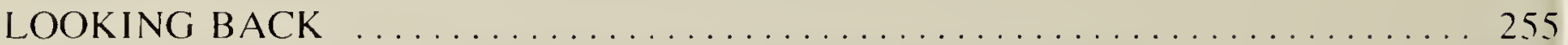

SNHS FINANCIAL STATEMENT - September $30,1975 \ldots \ldots \ldots \ldots \ldots \ldots$

\title{
REQUEST FOR SIGHTINGS OF COLOUR-MARKED SNOWY OWLS
}

This winter Snowy Owls will be live-trapped in the Saskatoon area and portions of the wings and tail will be dyed blue in order to study winter movements and behaviour. Anyone observing one of these owls should carefully note which areas are dyed since the dye will be applied in various combinations to the primaries, secondaries and tail in order to identify individuals. Since the colour-marking is most readily observed in flight, it may be necessary to flush an owl in order to

Coloured-marked Snowy Owls

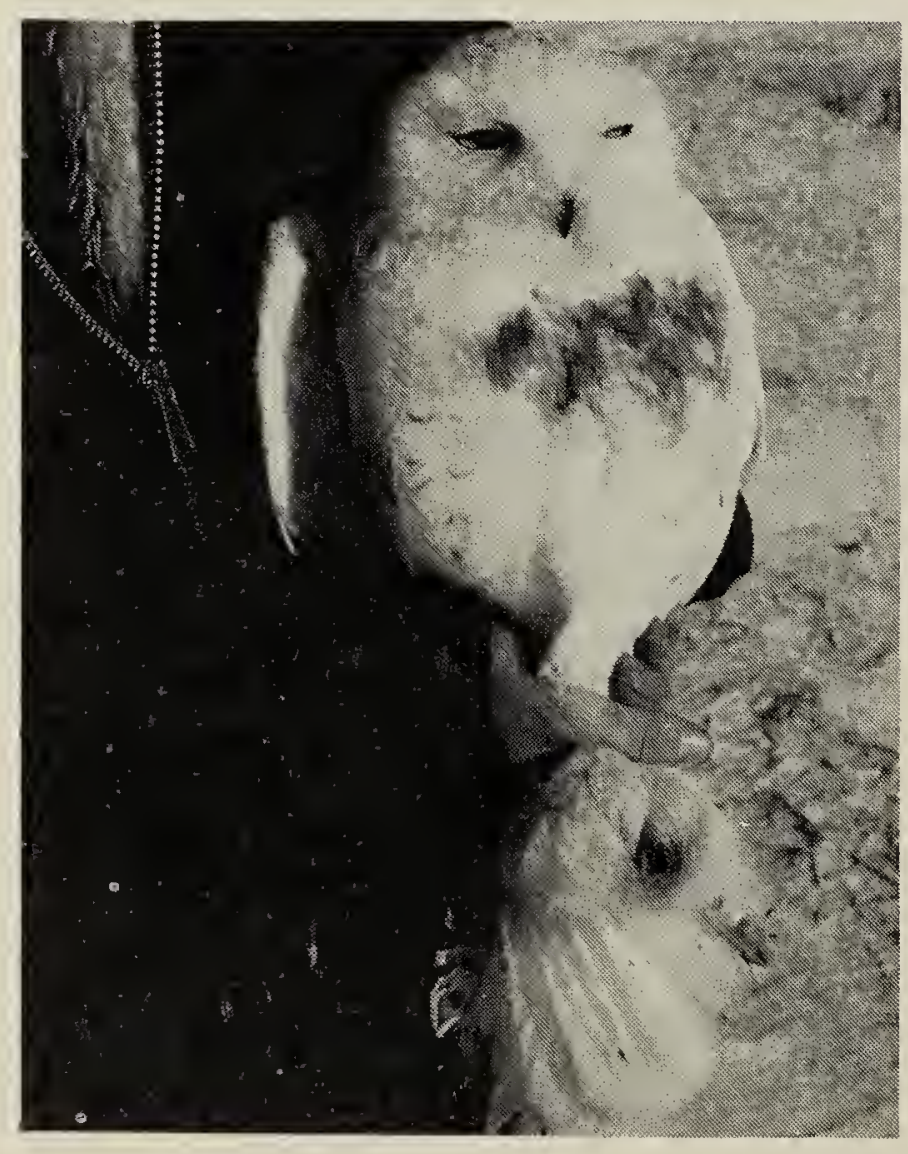

determine exactly what portions of it are dyed. However, people are requested not to continually flush or otherwise harass these marked birds since it may cause them to change their behaviour or to leave the area. The date, time, areas of blue and location of these sightings should be reported to

Adam Schmidt.

318 Ave. U North.

Saskatoon, Sask., S7L 3C7.

Telephones:

373-3933, 374-7808, 382-7984.

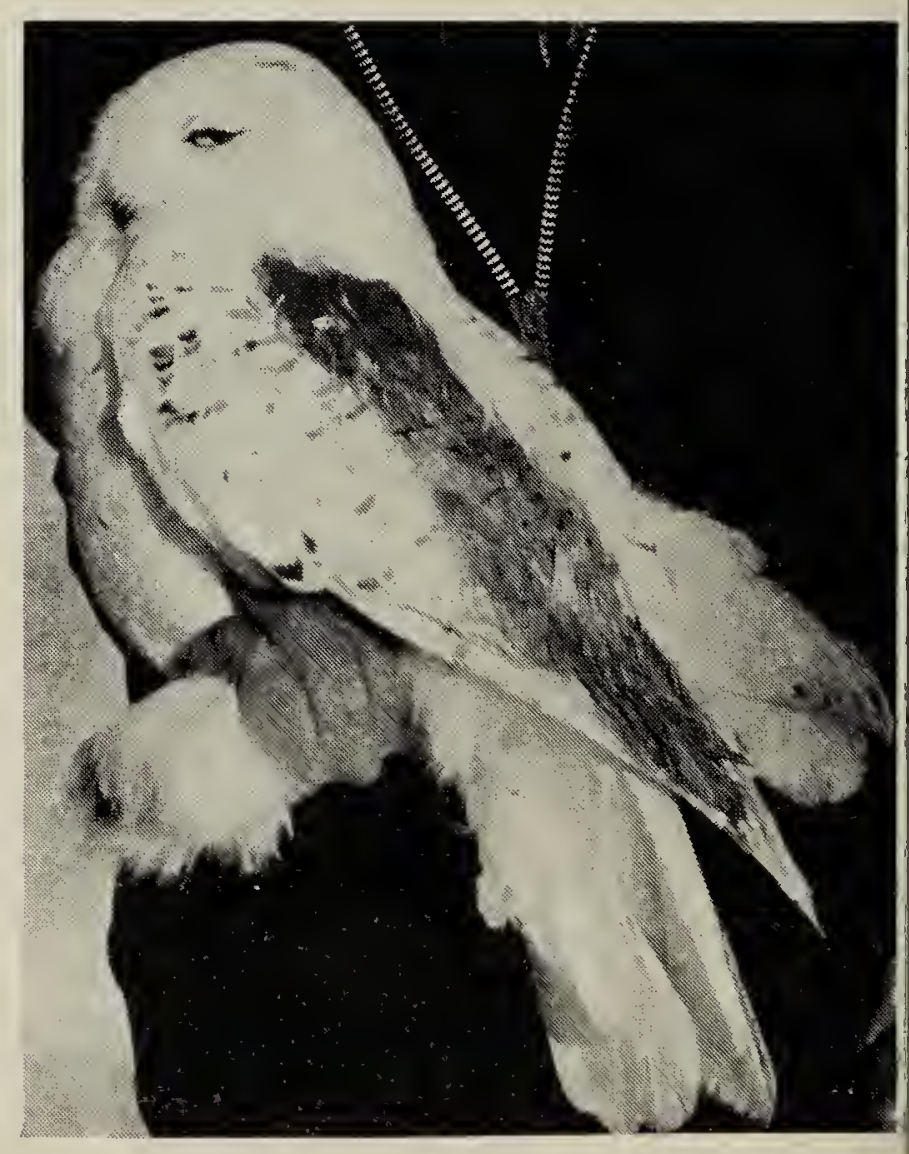

A. Schmidt 